\title{
MARKETING FARMACÊUTICO: RELAÇÃO DAS PUBLICIDADES TELEVISIVAS COM A AUTOMEDICAÇÃo
}

\section{PHARMACEUTICAL MARKETING: RELATIONSHIP OF TELEVISION ADVERTISING WITH AUTOMEDICATION}

\author{
Liana Maria Mazutti CARSONI'; Devanir Avigo JUNIOR ${ }^{2}$
}

1 - Acadêmica de graduação do curso de Farmácia do Centro Universitário Campos de Andrade, Curitiba, PR, Brasil. 2 - Farmacêutico e Professor Mestre do Curso de Farmácia do Centro Universitário Campos de Andrade, Curitiba, PR, Brasil. Autor para correspondência: lianamazutti@hotmail.com

\section{RESUMO:}

As indústrias farmacêuticas aplicam o marketing farmacêutico para dar publicidade aos medicamentos por elas comercializados e elevar o seu faturamento. No entanto, observa-se que a maioria das publicidades veiculadas em emissoras de televisão no Brasil apresenta algum tipo de infração legal. Com o objetivo de trazer ao conhecimento do profissional farmacêutico e demais profissionais da área da saúde tais ilegalidades, demonstrando como a publicidade pode se tornar um poderoso instrumento de indução a hábitos que elevam o consumo medicamentoso, afetando o tratamento terapêutico de maneira significativa, buscouse uma revisão da literatura em um levantamento bibliográfico, trazendo informações sobre o tema central, fazendo uma análise quanto à adequação deste tipo de publicidade com a legislação vigente e seus reflexos ao público alvo. Esse trabalho trás uma análise da normatização do país, e se a mesma se mostra eficiente. E ainda, demonstra alguns dos impactos, sociais e jurídicos da publicidade farmacêutica. Por fim, constata-se que a legislação atual não contempla de maneira satisfatória a prática da promoção televisiva de medicamentos, de modo a permitir a sua banalização como uma simples mercadoria, através de anúncios tendenciosos que fomentam o seu uso de maneira irracional.

Palavras-chave: marketing farmacêutico; publicidade de medicamentos; ética na publicidade; legislação do marketing; mídia televisiva.

\section{ABSTRACT:}

Pharmaceutical industries have been stepping up the use of pharmaceutical marketing to advertise the medicines marketed by them and raise their sales. Nevertheless, it is observed that the majority of the publicity transmitted in transmitters of television in Brazil present some type of legal infraction. With the objective of bringing to the attention of the pharmacist professional and other health professionals such illegalities, demonstrating how advertising can become a powerful induction tool to habits that increase drug consumption, affecting the therapeutic treatment in a significant way, a review of the literature was carried out in a bibliographic survey, bringing information about the central theme, making an analysis as to the adequacy of this type of advertising with the current legislation and its reflexes to the target public. This work brings an analysis of the normatization of the country, and if it is efficient. It also demonstrates some of the social and legal impacts of pharmaceutical advertising. Lastly, it can be seen that current legislation does not satisfactorily contemplate the practice of televised drug promotion, in order to allow its banalization as a mere commodity, through tendentious advertisements that encourage its use in an irrational way. Key words: pharmaceutical marketing; drug advertising; ethics in advertising; marketing legislation; television media. 


\section{INTRODUÇÃO}

O primeiro registro da palavra marketing se deu em 1902, nos Estados Unidos. Derivada da junção da palavra Market, que significa mercado, com a terminação da língua inglesa ing, que define movimento permanente; em tradução simples, marketing é mercado em movimento ou ação exercida no mercado (AJZENTAL, 2008).

A publicidade é uma das principais ferramentas do marketing empresarial; e o mercado farmacêutico brasileiro tem feito uso dessa ferramenta de gestão para comunicar a eficácia e a segurança dos produtos por ela comercializados (EÇA, 2012).

Não são raros os marketings criados sem levar em consideração os impactos que podem acarretar; afirmações que aparentemente podem parecer inócuas, como "único", "melhor", "garantido", embora possam auxiliar nas vendas, podem gerar conflitos de interesses e configurar publicidade enganosa ou abusiva (NYBO, 2015).

A literatura científica e os compêndios de farmacologia ensinam que todo fármaco possui significativo potencial de ameaça à saúde, acarretando reações adversas, intoxicações e até mesmo o óbito quando utilizado de maneira incorreta e indiscriminada (NASCIMENTO, 2007).

A regulação, feita posteriormente a veiculação da publicidade, não salvaguarda a população das informações incertas difundidas na mídia, normalmente em horários de maior audiência (NASCIMENTO; SAYD, 2005).

Diante das possíveis interferências a um tratamento aparentemente ineficaz, este trabalho objetiva apresentar ao profissional farmacêutico e demais profissionais da área da saúde, os principais fatores associados ao marketing das publicidades veiculadas no Brasil, que aliciam automedicação, e que possam estar afetando o tratamento do paciente através da indução a hábitos que elevam o consumo medicamentoso, bem como, proteger o telespectador da "(des)informação" veiculada na rede televisiva.

\section{METODOLOGIA}

Foram realizadas consultas a artigos científicos retirados das bases de dados eletrônicos do "CAPES", "Scientific Electronic Library Online" (SCIELO), "Biblioteca Digital Brasileira de Teses e Dissertações" (BDTD), priorizando os nacionais datados entre os anos de 2005 a 2018. Para tanto, os termos utilizados nas buscas foram: marketing farmacêutico; publicidade de medicamentos; ética na publicidade; legislação do marketing e mídia 
televisiva. Publicações de órgãos de regulamentação, leis, decretos e portarias também foram utilizados. Deste modo, foram encontrados mais de 200 artigos referentes ao tema; destes, foram selecionados 20 artigos, sendo utilizado como critério para escolha os que associavam o marketing das propagandas televisivas a automedicação, excluindo os que não faziam menção a legislação pertinente e em vigor.

\section{REFERENCIAL TEÓRICO}

\subsection{Automedicação}

Automedicação é a prática na qual o indivíduo, por iniciativa própria ou por aconselhamento de terceiros, faz uso de medicações para tratar ou aliviar sintomas. Ela envolve todas as classes de medicamentos; sejam os isentos de prescrição (MIP's), ou os que necessitam de receituário médico. Assim, automedicação consiste em adquirir o medicamento sem receita médica, compartilhar medicamentos com outros membros da família ou do círculo social, utilizar sobras de prescrições, reutilizar antigas receitas, descumprir a prescrição profissional, prolongar ou interromper precocemente o tratamento (CRUZ; CARAMONA; GUERREIRO, 2015).

De acordo com a Organização Mundial da Saúde (OMS), a automedicação é entendida como parte das ações de autocuidado que as pessoas fazem por si mesmas para estabelecer e manter a saúde, prevenir e lidar com a doença. É um conceito lato sensu, pois engloba higiene, nutrição, estilo de vida, fatores ambientais e fatores socioeconômicos (SOUZA et al., 2011).

No Brasil, inúmeras razões que levam a prática da automedicação, dentre as quais cabe citar: a legislação brasileira que define o medicamento de venda livre; o medicamento visto como uma mera mercadoria; as práticas mercantilistas das indústrias farmacêuticas; o sistema de saúde precário onde o acesso à população se torna restrito ao médico; o excesso de publicidades; a fácil aquisição; a venda indiscriminada para atingir metas comerciais; o grande número de estabelecimentos farmacêuticos; o consumo desenfreado do paciente na busca da solução para seu problema; a falta de esclarecimento nas propagandas e publicidades sobre efeitos danosos que os medicamentos podem carrear, a falta de comunicação médico/paciente e muitos outros (FERNANDES; MATOS, 2017).

No país, $20 \%$ dos medicamentos vendidos, são considerados essenciais para atender as necessidades de saúde da sociedade. E 35\% dos medicamentos 
comercializados são adquiridos sem a devida prescrição médica, tornando-se um problema de saúde pública (DAL PIZZOL et al., 2010).

Incorretamente utilizados, os medicamentos podem acarretar sérios riscos ao organismo, gerar intoxicações, dependência, seleção de bactérias resistentes, sangramento digestivo, reações de hipersensibilidade, elevar os riscos de neoplasias, entre outros malefícios (SOUZA; SILVA; NETO, 2008).

As prescrições de medicamentos, preparações magistrais e oficinais e outros produtos para a saúde, no Brasil, somente são permitidas a profissionais legalmente habilitados conforme leis específicas, sendo: Médicos (somente para uso humano Decreto 20.931/1.932); cirurgiões dentistas; médicos veterinários (somente para uso veterinário - Lei 5.517/68); farmacêuticos: medicamentos, de acordo com a Lista de Grupos e Indicações Terapêuticas Especificadas (GITE), isento de prescrição médica, protocolos e outras normativas técnicas estabelecidas pelo gestor municipal, fitoterápicos não tarjados e quando houver diagnóstico médico prévio ou quando da formalização de acordos de colaboração com outros prescritores e instituições de saúde. (Resolução nº 586/2.013 do Conselho Federal de Farmácia); nutricionistas: suplementos nutricionais e relacionados à prática do nutricionista. (Lei 8.234/91 e Resolução nº 402/2007 do Conselho Federal de Nutrição); biomédicos: produtos não considerados medicamentos. (Resolução nำ 204/2.001 do Conselho Federal de Biomedicina) e enfermeiros: medicamentos estabelecidos em programas de saúde pública e de acordo com rotinas aprovadas pela instituição de saúde em que trabalham ou outras normativas técnicas estabelecidas pelo gestor municipal. (Lei 7.498/86) (ANFARMAG, 2016).

O uso indiscriminado, inclusive dos medicamentos vendidos apenas sob prescrição médica, gera um alto índice de dependência e intoxicação. No entanto, os casos mais comuns no país, estão relacionados com o uso de tranquilizante e de anfetaminas, substância existente em moderadores de apetite. As autoridades na área da saúde constataram que mais de $30 \%$ dos casos de intoxicação dos brasileiros são causados por uso de medicamentos sem a devida prescrição médica (SOUZA et al., 2011).

\subsection{As Publicidades de Medicamentos X Automedicação}

A publicidade televisiva é uma ferramenta do marketing que só acarretará problemas se o objetivo comercial ultrapassar os limites éticos delimitados pela legislação. Muitos pesquisadores afirmam que a publicidade de medicamentos, enquanto estratégia 
persuasiva representa risco sanitário, caso não se comprometa com a divulgação de informação correta e segura. (ARAÚJO; BOCHNER; NASCIMENTO, 2012).

Essas atividades comerciais exercidas nas publicidades de medicamentos fazem parte da economia mundial, geram um cenário complexo e de grande importância, definindo padrões de mercado e de comportamento para a sociedade, incentivando o consumo e criando uma nova necessidade, desempenhando um impacto concreto nas atividades terapêuticas (SILVA; CORTE, 2009).

Oferecidos como mero produto do marketing industrial, os medicamentos são destaque em uso de recursos publicitários e possuem uma forte manifestação de persuasão. Estes recursos conciliam a marca do medicamento ao slogan publicitário, induzindo o telespectador à aquisição do "produto" divulgado. Sendo a mídia televisiva é a mais utilizada por fornecer maior retorno financeiro à indústria e por abranger maior número de telespectadores (AZEVEDO; PEREIRA, 2010).

Sob essa ótica, o marketing farmacêutico efetuado pelas indústrias e laboratórios de medicamentos faz das fragilidades do paciente, oportunidade de negócio e lucro. A promoção comercial de produtos para a saúde é extremamente eficaz, tornando o telespectador um potencial usuário (ANGELL, 2007).

Sua circulação televisiva pode desviar a real função do medicamento, ao divulgálo como um mero produto de consumo, cria uma demanda superior às reais necessidades, incentiva o consumo indiscriminado, induz a automedicação, agrava enfermidades e seus sintomas, acarreta em um dano financeiro devido a sua aquisição desnecessária, gera gastos ao Estado frente ao agravamento de patologias ou ocorrências de reações adversas (ANVISA, 2004).

Com quatro vezes mais farmácias do que o recomendado, o país vive a "cultura do medicamento" e uma das maiores preocupações diante do seu uso desorientado é a intoxicação. À frente dos produtos de limpeza, agrotóxicos e alimentos, os fármacos são os principais agentes de intoxicação humana no país. Em 2016, foram 158,46 mil casos registrados, totalizando 40,10\% dos apontamentos (SINITOX, 2018).

Os medicamentos são bens de saúde e não bens de consumo comuns, não podem ser anunciados como produtos de livre mercado, devem ser tratados como instrumentos de promoção, recuperação e manutenção da saúde e bem-estar (ASCOM/ANVISA, 2017).

Idosos, crianças e portadores de doenças crônicas formam um enorme contingente exposto a essas publicidades, quais geralmente, não contêm as advertências exigidas quanto ao uso de substâncias nocivas altamente prejudiciais a saúde (NASCIMENTO, 2007). 


\subsection{Legislação Pertinente, Normas Regulamentares e Fiscalização}

Para a divulgação de medicamentos na mídia televisiva existem regras e informações obrigatórias a serem seguidas, entre elas a advertência: "Ao persistirem os sintomas, o médico deverá ser consultado" (ASCOM/ANVISA, 2017).

A principal fonte de regulação das publicidades é o Código de Defesa do Consumidor - CDC. Seu artigo 37, trata da publicidade enganosa, sendo a que leva o consumidor a erro, podendo ocorrer de forma omissiva, comissiva, inteiramente falsa, parcialmente falsa ou exagerada (PIRES, 2016).

Configura publicidade enganosa por omissão, quando o anunciante omite dados relevantes sobre o que está sendo anunciado, que se conhecidas pelo cliente, não teria efetuado a compra, ou ainda, pagaria um preço inferior por ele. Já a publicidade enganosa por comissão é aquela no qual o fornecedor afirma algo que não condiz com a realidade, atribuindo mais qualidades ao produto ou ao serviço do que ele realmente possui. $E$ ainda, havendo mais de uma interpretação ao anúncio, basta para configurar sua ilicitude (NYBO, 2015).

Publicidade enganosa inteiramente falsa é a publicidade em que as informações são totalmente falsas, já a publicidade enganosa parcialmente falsa é a publicidade em que as informações são falsas somente em determinadas características; por exemplo: quando a propaganda promete coisas que o produto não faz, ou seja, não condiz com algumas funcionalidades (PIRES, 2016).

Encontra-se ainda, no art. $37, \S 2 .^{\circ}$ do CDC, a definição de publicidade abusiva, sendo considerada como tal, a publicidade discriminatória de qualquer natureza, a que incite à violência, explore o medo ou a superstição, se aproveite da deficiência de julgamento e experiência, desrespeite valores ambientais ou que seja capaz de induzir o consumidor a se comportar de forma prejudicial ou perigosa à sua saúde ou segurança. Nesses casos elencados sempre haverá ofensa aos valores sociais (COELHO, 2012).

A publicidade subliminar, uma modalidade que também é vedada pelo CDC, é aquela que não é perceptível ao telespectador à noção de estar sendo induzido à compra. Trata-se assim de manifestação reprovada por valer-se do subterfúgio do inconsciente do consumidor, induzindo-o a erro, cessando por completo sua liberdade de escolha (NYBO, 2015).

O art. 220, $\S 3^{\circ}$ da Constituição Federal menciona que a lei deve estabelecer os meios legais que garantam à pessoa e à família a possibilidade de se defenderem da 
publicidade de produtos, práticas e serviços que possam ser nocivos à saúde e ao meio ambiente. Motivo pelo qual, tais modalidades publicitárias possuem restrições de horários para sua veiculação (BRASIL, 1988).

As sanções administrativas cabíveis à publicidade ilícita é ação civil pública, que visa coibir tais práticas; a suspensão liminar da publicidade e a cominação de multa, além do meio cautelar de controle que é a contrapropaganda (BRASIL, 1988).

As sanções penais previstas nos art. 63 ao art. 69 do CDC, trata dos casos de omissão de dizeres ou sinais ostensivos sobre a nocividade ou periculosidade de produtos nas embalagens, invólucros ou publicidade, e afirmação enganosa sobre produto ou serviço, promover publicidade que sabe ou deveria saber que é enganosa ou abusiva ou não possuir dados fáticos, técnicos ou científicos que dão base à publicidade, são passíveis de ação pública incondicionada, pena de detenção e multa (COELHO, 2012).

O que muitos consumidores não sabem é que a publicidade enganosa é crime definido no artigo 67 do CDC e pode levar a uma pena de detenção de três meses a um ano e multa que se estende ao seu agenciador (PIRES, 2016).

A propaganda e a publicidade de medicamentos estão regulamentadas pela Resolução de Diretoria Colegiada da ANVISA (RDC) nํ. 96/2008. A monitoração e a fiscalização da publicidade de medicamentos no Brasil é competência da Agência Nacional de Vigilância Sanitária (ANVISA) determinada pela Lei nํ. 9782/99, que veio a reforçar o já estabelecido na Constituição Federal de 1988. No entanto, antes, a Lei nº. 6.360/76, já tratava da prática da publicidade de medicamentos e estabelecia a previsão de um regulamento ao tema, que levou a publicação da RDC n‥ 102/2000 (ANVISA, 2004).

\section{CONCLUSÃO}

Diante da polêmica que envolve o assunto que motivou a realização deste artigo, observa-se o grande desrespeito com a atual legislação, a dificuldade de abrangência da fiscalização sanitária e a irrisória penalidade para a indústria farmacêutica que se utiliza de publicidades ilícitas.

Desta forma, torna-se indispensável aos profissionais de saúde responsáveis pela prescrição e dispensação dos medicamentos, o conhecimento das possíveis interferências que a publicidade televisiva possa acarretar no tratamento farmacológico do paciente. Conhecendo o assunto, estes profissionais podem auxiliar na implantação de ferramentas capazes de tornar a regulação pública do setor de publicidade e propaganda de 
medicamentos mais eficiente e satisfatória, consoante com a atual Política Nacional de Medicamentos.

Cabe aos profissionais farmacêuticos promover o uso racional de medicamentos, o autocuidado à saúde, informar sobre os riscos e complicações que podem advir do uso indiscriminado de fármacos e, se necessário, encaminhar o paciente para atendimento médico, promovendo uma assistência à saúde responsável e eficaz.

Os farmacêuticos devem contribuir para a melhoria do cenário atual, prestando um serviço de atenção farmacêutica adequada a fim de diminuir ou minimizar, os agravos à saúde da população exposta a informações inadequadas, bem como, evitar abusos as normas legais brasileiras.

Por fim, ao Estado cabe promover a existência de fontes de pesquisa imparciais e oficiais sobre os medicamentos disponíveis no mercado, além de rigidez na fiscalização e punição severa a quem faz uso de publicidades ilícitas.

\section{REFERÊNCIAS}

ASSOCIAÇÃO BRASILEIRA DE NORMAS TÉCNICAS. NBR 6023: informação e documentação - referências - elaboração. Rio de Janeiro, 2002.

AJZENTAL, Alberto. História do pensamento em marketing. Editora Saraiva, 2017.

ANVISA. Agência Nacional de Vigilância Sanitária. Resolução da diretoria colegiada - RDC no 96, de 17 de dezembro de 2008. Disponível em:< www.anvisa.gov.br/legis> Acesso em: 19 de out. de $2017 a$.

ANVISA. Agência Nacional de Vigilância Sanitária. Resolução da diretoria colegiada - RDC $\mathbf{n}^{\circ} \mathbf{1 0 2}$, de 30 de novembro de 2000. Republicada por ter saído com incorreção, do original, no Diário Oficial da União $n^{\circ} 231-E$, de 1\%12/2000, Seção 1, pág. 28. Disponível em: <www.anvisa.gov.br/legis> Acesso em: 19 de out. de 2017b.

ANVISA. Agência Nacional de Vigilância Sanitária. Propagandas de Medicamentos no Brasil. 2004. Disponível em: <http://www.anvisa.gov.br/propaganda/apresenta_projeto_ monitora.pdf>. Acesso em: 12 de out. de 2017c. 
ANFARMAG - Associação Nacional de Farmacêuticos Magistrais. Guia Prático de

Prescritores Habilitados e Prescrições. 2016. Disponível em: <http://http://fqm.edu.br/ 20161/wp-content/uploads/2017/02/ANFARMAG-Guia_pratico_de_prescritores_habilitados _e_prescricoes.pdf>. Acesso em: 19 de out. de 2017.

ASCOM/ANVISA - Agencia Nacional de Vigilância Sanitária. Consumo de medicamentos: informação é o melhor remédio. 2017. Disponível em: <http://portal.anvisa.gov.br/noticias>. Acesso em: 19 de out. de 2017.

AZEVEDO, Germana Santos ${ }^{1}$; PEREIRA, Orcione Aparecida Vieira. Análise da publicidade das propagandas de medicamentos veiculadas em emissoras de televisão. Farmácia \& Ciência, v. 1, n. 1, p. 3-15, 2010.

BRASIL. Constituição (1988). Constituição da República Federativa do Brasil: Organização de Alexandre de Moraes. 16.ed. São Paulo: Atlas, 2000.

BRASIL. Decreto n 20.931, de 11 de janeiro de 1932. Regula e fiscaliza o exercício da medicina, da odontologia, da medicina veterinária e das profissões de farmacêutico, parteira e enfermeira, no Brasil, e estabelece penas. Diário Oficial da União, Brasília, Seção 1 15/1/1932, Página 885.

BRASIL. Lei n 5.517, de 23 de outubro de 1968. Dispõe sobre o exercício da profissão de médico-veterinário e cria os Conselhos Federal e Regionais de Medicina Veterinária. Brasília, DF, 23 de outubro de 1968. Lex: coletânea de legislação: edição federal, São Paulo, v. 7, 1976. Suplemento.

BRASIL. Lei $\mathrm{n}^{\circ}$ 6.360, de 23 de setembro de 1976. Dispõe sobre a vigilância sanitária a que ficam sujeitos os medicamentos, as drogas, os insumos farmacêuticos e correlatos, cosméticos, saneantes e outros produtos, e dá outras providências. Diário Oficial da união, Brasília, 24 de setembro de 1976.

BRASIL. Lei n 7.498, de 25 de junho de 1986. Dispõe sobre a regulamentação do exercício da Enfermagem e dá outras providências. Diário Oficial da União, Brasília, Seção I - fls. 9.273 a 9.275 . 
BRASIL. Lei. 8.078 de 11/09/9. Código de Defesa do Consumidor. Diário Oficial da União, Brasília, DF, 1990.

BRASIL. Lei n 8.234, de 17 de setembro de 1991. Regulamenta a profissão de nutricionista e determina outras providências. Diário Oficial da União, Brasília, DF, 17 de setembro de 1991.

BRASIL. Lei no․ 9782, de 26 de janeiro de 1999. Define o Sistema Nacional de Vigilância Sanitária, cria a Agência Nacional de Vigilância Sanitária, e dá outras providências. Diário Oficial da União, Brasília, v. 1, n. 18, 27 de janeiro de 1999.

CAPES. Coordenação de Aperfeiçoamento de Pessoal de Nível Superior. Portal de Periódicos. 2017. Disponível em: <http://www.periodicos.capes.gov.br>. Acesso em: 19 de outubro de 2017.

COELHO, Claudia Schroeder. Publicidade enganosa e abusiva frente ao Código de Defesa do Consumidor. Jus Navigandi, Teresina, v. 6, 2012.

CRUZ, Pedro Soares; CARAMONA, Margarida; GUERREIRO, Mara Pereira. Uma reflexão sobre a automedicação e medicamentos não sujeitos a receita médica em Portugal. Revista Portuguesa de Farmacoterapia, v. 7, n. 2, p. 83-90, 2015.

DAL PIZZOL, Tatiane da Silva et al. Adesão a listas de medicamentos essenciais em municípios de três estados brasileiros. Cadernos de saúde pública. Rio de Janeiro. Vol. 26, no. 4 (abr. 2010), p. 827-836, 2010.

DA SILVA, Renata Britto; CORTE, Temis Weber Furlanetto. A propaganda de medicamentos e sua adequação conforme a RDC 96/2008. Revista da Graduação, Publicação de TCC da Pontifícia Universidade Católica do Rio Grande do Sul, v. 2, n. 2, 2009.

DE BIOMEDICINA, Conselho Federal. Resolução n 204 de 18 de outubro de 2011. Revoga ad referendum do Plenário, a Resolução CFBM no 070, de 30 de novembro de 2001. Disponível em: <http://www.normasbrasil.com.br/norma/resolucao-2042011_114469.html>. Acesso em: 19 de outubro de 2017. 
DE FARMÁCIA, Conselho Federal. Resolução no 585 de 29 de agosto de 2013. Regulamenta as atribuições clínicas do Farmacêutico e dá outras providências. Diário Oficial da União, v. 29, 2013.

DE NUTRIÇÃO, Conselho Federal. Resolução $n^{\circ} 402$ de 30 de julho de 2007. Regulamenta a prescrição fitoterápica pelo nutricionista de plantas in natura frescas, ou como droga vegetal nas suas diferentes formas farmacêuticas, e dá outras providências. Disponível em: <http://www.cfn.org.br/index.php/legacy-1734/>. Acesso em: 18 de outubro de 2017.

EÇA, Vitor Brandão. A propaganda de medicamentos e a evolução do mercado farmacêutico. Revista UPpharma, n. 137, ano 35, p. 48-49, 2013.

FERNANDES, Deise Luci; MATOS, Luana Amancio de. A Relação da Propaganda de Medicamento e a Automedicação. 2017.

FERREIRA SOUZA, Layz Alves et al. Prevalência e caracterização da prática de automedicação para alívio da dor entre estudantes universitários de enfermagem. Revista Latino-americana de enfermagem, v. 19, n. 2, 2011.

NASCIMENTO, Álvaro César; SAYD, Jane Dutra; "Ao Persistirem os Sintomas, o Médico Deverá Ser Consultado". Isto é Regulação? PHYSIS-Revista de Saúde Coletiva, v. 15, n. 2, 2005.

NASCIMENTO, Álvaro. Propaganda De Medicamentos: Como Conciliar Uso Racional e a Permanente Necessidade De Expandir Mercado?. Fundação Oswaldo Cruz, Escola Politécnica de Saúde Joaquim Venâncio, Revista Trabalho, Educação e Saúde, v. 5, n. 2, p. 189-250, 2007.

NYBO, Erik. Propaganda enganosa: quais os impactos jurídicos?. Disponível em: $<$ https://www.ecommercebrasil.com.br/artigos/propaganda-enganosa-quais-os-impactosjuridicos/\#>. Acesso em: 01 de setembro de 2017.

PIRES ARAÚJO, Carolina; BOCHNER, Rosany; NASCIMENTO, Álvaro César. Marcos 
legais da propaganda de medicamentos: avanços e retrocessos. Physis-Revista de Saúde Coletiva, v. 22, n. 1, 2012.

PIRES, Cleide Valla. As mais diversas formas de propaganda enganosa. 2016. Disponível em: <https://www.jusbrasil.com.br/artigos/?ref=navbar> Acesso em: 18 de outubro de 2017.

SINITOX. Sistema Nacional de Informações Tóxico - Farmacológicas. Tabela 10 - Evolução dos Casos Registrados de Intoxicação humana por Agente Tóxico - Brasil - 2016. Rio de Janeiro. 2016. Disponível em: <https://sinitox.icict.fiocruz.br>. Acesso em: 13 abril de 2018.

SOUSA, Hudson WO; SILVA, Jennyff L.; NETO, Marcelino S. A importância do profissional farmacêutico no combate à automedicação no Brasil. Revista eletrônica de farmácia, v. 5, n. 1, 2008. 